\title{
Paradigm of Development of Economic and Social Systems and Decent Work Provided in the Context of Systemic Changes
}

\author{
Victorya Kompaniets $^{1 *}$, Vadim Danilyan ${ }^{2}$ and Larisa Shulgina ${ }^{3}$, Volodymyr Pavlichenko ${ }^{4}$ and \\ Boris Ostapuk ${ }^{1}$ \\ ${ }^{1}$ Ukrainian State University of Railway Transport, Department of Economics and Management of \\ Industrial and Commercial Business, 61000, Feuerbach Square, Kharkov, Ukraine \\ ${ }^{2}$ Ukrainian State University of Railway Transport, Department of Philosophy and Sociology, 61000, \\ Feuerbach Square, Kharkov, Ukraine \\ 3 "Voronezh State Technical University", Department of Economics and Fundamentals of \\ Entrepreneurship, 394000, $20^{\text {th }}$ Anniversary of October St., 84, Voronezh, Russian Federation \\ ${ }^{4}$ Kharkiv Institute of Finance Kyiv National University of Trade and Economics , Pletnevsky lane 5, \\ 610500 Kharkiv, Ukraine
}

\begin{abstract}
The article deals with the reasonable grounds for the idea of required transformations not only at social and economic level, but initially the changes should be realized at non-economic level, in order to provide the development of economic and social systems and decent work in the context of systemic changes. This approach involves the choice of a non-linear progress paradigm, transformation of the values for top-managers and entrepreneurs and society as a whole, formation of rules and incentives within the institutional system of national states and international community, being aimed at reorienting the economy towards human oriented direction.
\end{abstract}

\section{Introduction}

At present, we face the profound transformation of worldwide and national economic and social systems under the impact of qualitative technological, cultural and demographic shifts.

Those factors involve such global risks as: altering the meaning and essence of Labour; increasing unemployment and migration, regional and gender difference in work environment; growing poverty and social and financial differentiation, social and economic and political instability; aggravated inability to control the economic and social systems at their critical level.

In order to reduce such risks and provide the qualitative development of economic and social systems, as well as to guarantee the decent work for all the employable members of society; only joint efforts of the entire world community would be able to realize it. The state of affairs becomes even more complicated due to the fact that such transformations are required not only at social and economic level, but initially the changes should be realized at non-economic level,

\footnotetext{
* Corresponding author: victorya.kom.ek@gmail.com
} 
including the related changes in the paradigm of development of economic and social systems, along with the values for top managers and entrepreneurs and society as a whole. However, the necessity and priority of non-economic changes has been comprehended by few representatives of science, economics and politics only.

Therefore, in this publication we are going to provide the reasonable grounds for necessity and priority of such changes, as well as to demonstrate the interaction of non-economic and economic transformations at the stage of development of economic and social systems and the decent work provided herewith.

\section{Research results}

Unfortunately, the linear development paradigm dominates over the social theory and economic and social policy in contemporary society. Thus, the basis for further progress is being formed with the material component, i.e. the development in the fields of technology and economy goes on, while the cultural and moral standards of society are considered to be the "secondary" values, and the human being is considered to be not a goal but an instrument for transformation. However, such a policy that applies the economic or technological criteria in order to evaluate its success will result in fatal losses for environment, economy and humans themselves.

There is another type of a paradigm, i.e. a non - linear one, when the social culture is the basis for social development and its main estimation criterion (to wide extent, it comprises the level of morality, education, scientific development) and harmonious human development. Only a moral and educated person is able to determine the criteria related to the utility of engineering and technology and make it profitable for the whole society. Moreover, economic activity, which could be developed upon the profit-motivated basis without any moral restrictions, will result in further corruption and economic crimes, which could not be eliminated by any legal regulations.

This opinion related to the progress of society is based on ideas by N. Ya. Danilevskiy, P. A. Sorokin, A. Toynbee, F. List, as well as of the representatives of the German Historical School of Economics and the Eastern Slavic School of Economic Thought. The contemporary authors, who work in the framework of this paradigm, are J. K. Galbrait, I. Wallerstein, G.V. Zadorozhniy, V. Yu. Katasonov, A. S. Panarin, Yu. M. Osipov.

We should mention one of the works belonging to the historical heritage: it's one of the main concepts of the Eastern Slavic School related to the production factors, along with the similar idea by the researcher V. Sombart regarding the structure of economic and social system (the terms is called "economic system" according to the author's terminology).

The representatives of the Eastern Slavic School believed that the fourth (a non - economic) factor was the main production factor which used to determine the efficiency of application of another factors (as related to the work, nature and capital). They called it as "cultural and historical people's forces" or "spiritual and moral capital", as it united the spirit of the people, their culture and values [1, p.87].

According to V. Sombart's opinion, he defined the concept of economic system like "some spiritual unity that 1) penetrated with certain spirit or became involved into a certain meaning; 2) had a certain order and organization, and 3) applied a certain technique "[2]. That is, according to V. Zombart's opinion, the main element of the economic and social system is its spirit as a spiritual and cultural component which determines the national way of thinking, activity, motivation and psychology of economic activities of its subjects, in particular, organization of all the economic subsystems, regime of ownership and labor, application of engineering and technological approach. Such provisions require the circumstances for priority development of spiritual and moral capital of society, in comparison with its technical and economic development.

The non-linear paradigm approach became the background for the last published research work by J. K. Galbraith "The Economics of Innocent Fraud" [3], and the final report by the Global Commission on the Future of Work titled "Work for a Brighter Future" [4]. 
The authors of the Report (i.e. the experts of the International Labour Organization, ILO) underline that a human being and his work are the centers of economic and social policy and business practices [4, p. 27]. The authors draw our attention to the problem of destructive nature of technological changes and fundamental shifts in the field of labor, they invited all the parties involved to take responsibility in relation to the provision of economic and social development and decent work. Besides, they highlight the issue of new evaluation criteria for progress which reflects the human development, as well as guarantee the social justice, environmental protection, that is, the implementation of humanitarian, social and environmental goals of the economic and social system.

However, if the ILO experts only raised the problem related to criteria, yet the author J. K. Galbraith had already denied the basic concept of economic determinism in general, as it reflects the linear development paradigm related to the evaluation criteria for progress in the development of society. In compliance with contemporary economic theory and practice, the main criteria for progress are quantitative criteria of economic development. Nevertheless, J. K. Galbraith believed that "the practice to evaluate the progress of society with the indicators of production volume and GDP growth is not an innocent mistake" [3, p. 32]. The researcher underlined that the most significant achievements in the history of mankind took place in those societies whose criteria for success were the development of religion, culture and science. Unfortunately, according to J. K. Galbraith's opinion, the highest achievement of today's civilization is its total destruction.

We should realize that all human activities are regulated by two institutions: law (legislation) and moral standards. Basically, when we mean the rules and incentives in the field of Economics, then certain legislative changes are implied. However, they are not sufficient. The authors K. Homann and F. Blome-Drees reasonably argued that the acts of legislation can't be perfect enough, in terms of their ability to cover all the aspects of moral requirements. This process is caused by the impact of the factors of systemic arrangement, in particular: reactive character of institutional framework; unsatisfactory system of control over the implementation of legislative regulations; probability of conflict between legislation and moral standards; "increasing decline of competence in politics and the particular order in politics" [5, p. 276].

Therefore, those top - managers and entrepreneurs, who regulate the implementation of economic, technical or other policies should take moral responsibility for their decisions. The requirements for regulating the economic activities (both by the legal criteria and moral standards) involve the development of institutional and individual ethics.

In terms of material components of economic transformations related to the field of Labour and economy as a whole, we should discuss the fundamental changes in the investment policy of the state. However, we are going to demonstrate that all those transformations are also associated with the impact of non-economic factors.

The experts of the ILO identify three main investment trends: development of human abilities; institutions of labor market; decent and secure employment.

The investments in the field of decent and secure employment require the priority development of the real economy sector. This is a vital issue, because the contemporary economy, having become oriented at the speculative and debtor's approach, turned to be extremely inefficient, along with the actual risk of experiencing new crisis. At the same time the transition from financial speculations to development of the real sector is associated not only with economic incentives, but with the changing motivation and values for investors and entrepreneurs, i.e. it means the transition step from personal gain to the goals of creation and service to our society.

The proper examples can be the goals and motivation of business activities that had been realized by $\mathrm{H}$. Ford, he was famous to have achieved tremendous success in his practices. $\mathrm{He}$ believed that the real objective of business activities should serve the people and society: "The ultimate well - being of a manufacturer also depends on the benefits to be brought to the people" [6]. He believed that human greed was some kind of "myopia" and declared the goal of his manufacture as "providing the maximum purchasing power" at the expense of cost savings, high 
payments of labour and marginal profits.

We should underline that the development of the real sector should be promoted on the basis of digital technologies as well. However, the implementation of new technologies in manufacturing sector (i.e. robotization, automation, artificial intelligence systems) involves significant risks. We'd better specify those risks: elimination of jobs; extremely inequitable distribution of technological dividends in favor of high-tech companies and highly skilled employees; significant gaps in training of the employees who should meet the requirements of new economy; decrease in degree of independence and control of the employees due to the automation, depreciation of their labor content, which might cause the loss of their skills and decrease in degree of their job satisfaction; exceeding exploitation of the employees who deal with digital platforms, greatly due to the absence of any international labour regulations for the employment practices to be realized on digital platforms; risks of disclosing the privacy of the employees due to the new technologies which generate large amount of data related to the employees [4,7]. Therefore, we should introduce and implement new technologies, taking into consideration the minimization of such risks and "adopting an approach to the management of artificial intelligence in compliance with the principle: "it's a human being who controls", it means that any final decisions, which might affect the labour model, shall be made by human beings only, not by the related algorithms" [4, p. 51].

The employment career of a person is characterized by some transition stages: starting from a certain education level and obtaining related skills up to his labour activities; transfer from one job to another, fundamentally new position; transition from employment to retirement. Their complex character is aggravated by continuous worldwide transformations. In order to make people strong enough to manage those changes, it's necessary to increase the investments in institutions, policies and strategies that could support people during such transition periods in future labour environment [4, p. 61].

The quality of education is a key factor in providing the employment opportunities and "smooth" transitional periods. The joint efforts taken by the state authorities, employers, educational institutions and society as a whole should be required, in order to create and support the development of the educational system throughout human life. However, the classical educational system should become its foundation, while the "new opportunities for broad participation in professional training, as well as opportunities to overcome time and resource limits" will introduce new digital technologies. Nevertheless, the high quality education can be provided with special quality programs, methods and training results, along with the universal access available for anyone. The properly trained teachers are highly demanded, because "whose skills, experience and tutorship could not be ever replaced by any technology", financial provision, creation of monitoring system and "a common system of recognition of qualifications and skills at the national and international level(s)" [4, p. 36].

Thus, one independent and complicated issue should be mentioned in relation to the sources of investment of the above - mentioned reforms in the field of Labour. In our opinion, the country should provide the primary mobilization of its internal resources. It's possible to establish the national development banks for strategic investments, in order to provide further accumulation of resources.

In this respect, a significant source for accumulation is prevention of the "drain" of resources in the form of illegal transfers of funds abroad. Indeed, one of the serious shortcomings of the existing economic system is the funds to have been stored on offshore accounts without any tax payments. The experts believe that the regular annual loses of the US budget is at least 100 billion USD, due to the offshore activities of the American companies. The biggest "tax evader" is the Company "Apple Inc."; it is estimated that at the beginning of year 2015, the amount equal to 181,1 billion USD was kept in its offshore assets. The amount of corporate tax savings (and, those are the losses of the US Treasury, accordingly) was estimated at 59,2 billion USD [8]. Moreover, according to the estimate presented by the International Monetary Fund (IMF), nearly $40 \%$ of all foreign direct investment in the amount of 12 trillion USD turns to be "artificial": those assets are the financial investments made through the "dummy corporations" 
that never deal with any actual activities [9].

An additional resource for investing in the economic development and providing the decent work is reduction of the level of corruption. According to the data presented by the United Nations Organization, the actual corruption (including the losses involved for the world economy in the annually amount equal to 2,6 trillion USD) is more than 5\% of global GDP [10]. Corruption incurs real damage to social and economic development in all the countries all over the world. Thus, the annual corruption (including the losses involved for the European Union) amounts to 120 billion EUR, which could be compared to the amount of Ukraine's GDP [11].

The proper involvement of investment assets to the development of the national economy would be impossible without provision of the favorable domestic business climate and reorientation of business activities towards long - term investments in real economy and resolving the social problems. This approach requires both changes in psychology of a modern entrepreneur through special educational programs, as well as modifications of the state economic policy, it should direct the business activities towards long - term programs for development of the real economy sector and resolving the social problems through the reasonable tax policy.

Such a policy also implies reasonable taxation of economic subjects, in particular, that for the large corporations, medium and small entities; unfortunately, this approach has not been currently observed. Thus, over the past three decades in the countries of the Organization for Economic Cooperation and Development (OECD) the average corporate tax rates have been decreased from $45 \%$ in the middle 1980 -ies up to $24 \%$ in 2018 . This fact resulted in decrease in the share of corporate taxes in total government revenues and, according to the data presented by the Secretary General of OECD, raised "difficult issues" for those governments that used to seek the provisions for vital public services, social programs and infrastructure [quotation in 4, p. 74].

One of the most significant obstacles for the implementation of policies aimed at the development of a human being, provision of his decent work and environmental safety is the concentration of power by the authorities of contemporary technology companies which develop their policies based on intention to gain super-profits at any cost, even due to the violation of a human right to the decent work for all the citizens of the planet.

Nowadays the largest digital corporations operate according to the slogan: "the winner takes the greatest benefit'; the earnings appear due to the advantages of the "pioneers" and monitoring, analytical options for mass data and the "scale effect from the demand side" [12].

However, we're talking not about the high-tech companies only, but we mean the transnational companies (TNCs) as a whole. According to J.K. Galbraith, the corporate authorities, being motivated by their power and enrichment, actually impose such values upon the society that cause its gradual degradation. "Corporate authorities declare that the success of society means acquiring even more cars, TV sets, various clothes and other consumers' goods, along with buying even more and more lethal weapons. This is the measure of human achievements. Such negative consequences for society as environment pollution, destruction of natural landscape, unprotected health and civil rights, threating military acts and devastation are not taken into consideration" [3, p. 82]. Giving a moral assessment of the activities of TNCs, the well-known Western politician and researcher J.P. Buchanan called the transnational corporations (TNC) "Cain of our time" [13].

Thus, considering the directions of changes in investment policy to ensure qualitative transformations, again we face the question of the dramatic dependence of economic and social development on the moral qualities of those persons who deal with economic activities and actually need to change the situation.

\section{Conclusion}

By way of summing up, in this publication we have demonstrated that, under the circumstance of systemic changes, the provision of development of economic and social systems and decent 
work for all the members of society would be impossible without revising the progress paradigm which has been dominating over the theory, consciousness and politics, as well as without further transformation of the values for top-managers, entrepreneurs and society as a whole. It should involve the systemic changes in culture, politics and economics, both at the level of national states and international activities.

The cultural shifts should involve transformations in public opinion, when a human being becomes the main value and goal of the further transformations, while technological and economic development would become their instruments, and the economic activity would be evaluated in accordance with the moral standards and stipulated not only by the legislation, but also by those standards, namely. The alterations in goal setting and value system, the view of priority for non-economic factors within the development of economic and social systems are the key points to change the activities of top managers and entrepreneurs, and, therefore, the key to the existing model of economic and social development and provision of decent work.

It is necessary to set the rules and incentives that provide the economy reorientation towards the human - oriented direction within the entire institutional system of national states and international community.

\section{References}

1. V. V. Kompaniets, Eastern Slavic Economic Thought in Modern Economic Science and Education, Social Economy, Ed.1, 2(48), 84-95 (2014)

2. W. Sombart, Selected Texts (2005). Available at https://www.litres.ru/vernerzombart/izbrannye-raboty/chitat-onlayn/page-6/ (accessed January 23, 2019)

3. J. Kenneth Galbraith, The Economics of Innocent Fraud: Truth for Our Time, 88 (Publishing House "Europe", Moscow, 2009)

4. Work for a Brighter Future. Global Commission on the Future of Work. International Labour Organization (2019). Available at https:/www.ilo.org/global/topics/future-ofwork/publications/WCMS_662410/lang--en/index.htm (accessed January 23, 2019)

5. B. Sutor, K. Homann, F. Blome-Drees, Political and Economic Ethics, transl. by $S$. Kurbatov, K. Kostyuk, 368 (Grand-Fair, Moscow, 2001)

6. H. Ford, My Life, My Achievements (2013). Available at http://knigosite.org/ library/read/7121 (accessed January 15, 2019)

7. Issue Briefs No.6 The Impact of Technology on the Quality and Quantity of Jobs. Global Commission on the Future of Work. International Labour Organization (2018). Available at https:/www.ilo.org/wcmsp5/groups/public/---dgreports/---cabinet/documents/

publication/wcms_618168.pdf(accessed February 22, 2018)

8. V. Yu. Katasonov, Some Figures to Prove that the State Supports Business in the USA, not vice versa (2017). Available at https://www.nakanune.ru/news/2017/4/14/ 22467004 (accessed April 14, 2018)

9. J. Damgaard, T. Elkjaer, N. Johannesen, Piercing the Veil, Finance \& Development, Vol. 55, No. 2, 50-53 (2018).

10. The Costs of Corruption: values, economic development under assault, trillions lost, says Guterres (2018). Available at https://news.un.org/en/story/2018/12/1027971 (accessed December 9, 2018)

11. Amount of Corruption in the EU is Equal to Ukraine's GDP (2013). Available at http://podrobnosti.ua/892231-razmery-korruptsii-v-es-ravny-vvp-ukrainy.html (accessed March 7, 2018)

12. Trade and Development. Report 2018. Power, Platforms and Free Trade Delusion. Chapter III, Economic Development in a Digital World: Prospects, Pitfalls and Policy Options. New York and Geneva (2018). https://unctad.org/en/PublicationChapters/tdr2018ch3_en.pdf (accessed September 26, 2018)

13. Patrick J. Buchanan, The Death of the West (2003). Available at 
https://royallib.com/book/byukenen_patrik/smert_zapada.html (accessed October 23, 2018) 